\title{
COMPARISON OF BASELINE BRACHIAL ARTERY MEASUREMENTS AND EFFECT ON PEAK FLOW-MEDIATED DILATION
}

\author{
A THESIS \\ SUBMITTED TO THE FACULTY OF THE GRADUATE SCHOOL \\ OF THE UNIVERSITY OF MINNESOTA \\ BY: \\ Joseph Dwayne Ostrem \\ IN PARTIAL FULFILLMENT OF THE REQUIREMENTS \\ FOR THE DEGREE OF: \\ Master of Science
}

ADVISOR: Donald R. Dengel, Ph.D.

August 2013 


\section{Copyright Page}

(C) Joseph Dwayne Ostrem 2013. All rights reserved. 


\section{ACKNOWLEDGEMENTS}

The following thesis was prepared under the direction of Donald R. Dengel, Ph.D., Eric M. Snyder, Ph.D., and Aaron S. Kelly, Ph.D., at the University of Minnesota, as well as the assistance of Julia Steinberger, M.S., M.D., and Kara L. Marlatt, M.S. 


\begin{abstract}
The aim of this study was to examine the effect of pre-occlusion, occlusion, and postocclusion baseline brachial artery measurements on the calculation of peak flow mediation dilation (FMD). Ultrasound imaging of the brachial artery following reactive hyperemia was conducted in 418 children and 533 adults. Baseline brachial artery measures were a 10-second average before (pre-occlusion), during (occlusion), and after (post-occlusion) hyperemia. Peak FMD was defined as the change from baseline to the peak brachial artery diameter following reactive hyperemia. Pre-occlusion, occlusion, and post-occlusion baseline measures of brachial artery diameter were not significantly different in children $(3.15 \pm 0.51,3.14 \pm 0.50$ vs. $3.11 \pm 0.50 \mathrm{~mm}, \mathrm{P}=0.179)$ or adults $(3.81 \pm 0.72,3.81 \pm 0.73$ vs. $3.79 \pm 0.73 \mathrm{~mm}, \mathrm{P}=0.201)$. Peak FMD values were not significantly different when calculated from pre-occlusion, occlusion, or post-occlusion baselines in children $(6.77 \pm 5.78,6.93 \pm 4.03$ vs. $7.85 \pm 3.62 \%, \mathrm{P}=0.208)$ or adults $(6.06 \pm 5.53,6.12 \pm 3.94$ vs. $6.62 \pm 3.70 \%, P=0.266)$. We found no differences in FMD regardless of the baseline brachial artery diameter used in children or adults. Therefore, comparison of data from studies utilizing different measures of baseline brachial diameter can be conducted without correction of data.
\end{abstract}

Key words: Ultrasound, Endothelium-Dependent Dilation, Vascular Function. 


\section{TABLE OF CONTENTS}

Acknowledgements................................................ i

Abstract............................................................. ii

Table of Contents........................................................ iii

List of Tables........................................................ iv

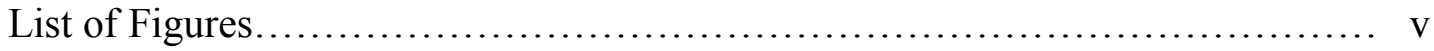

Chapter 1. Introduction.............................................. 1

Chapter 2. Review of Literature....................................... 5

Assessing Vascular Function.................................... 7

Physiological Response to Reactive Hyperemia...................... 8

Endothelium-Dependent Dilation..................................... 9

FMD Technique.............................................. 11

Chapter 3. Methodology............................................... 13

Experimental subjects.......................................... 14

Physical Assessment........................................... 14

Vascular Assessment........................................... 15

Statistical Analysis................................................. 16

Chapter 4. Results................................................... 18

Chapter 5. Discussion.................................................. 20

Chapter 6. Conclusion.............................................. 25

Chapter 7. References.............................................. 27 


\section{LIST OF TABLES}

Table 1. Mean ( \pm Standard Deviation of the Mean) Demographic

Characteristics........................................................ 38 


\section{LIST OF FIGURES}

Figure 1. Mean ( \pm standard error) baseline brachial artery and flow-mediated dilation comparison measures for children and adults 39 


\section{CHAPTER 1. INTRODUCTION}


Dysfunction of the endothelium is commonly associated with increased cardiovascular risk and atherosclerosis (Vita and Keaney, 2002), as well as increasing age (Gerhard et al., 1996), gender (Kapuku et al., 2004; Juonala et al., 2008), cigarette smoking (Lekakis et al., 1998), and obesity (Tounian et al., 2001; Williams et al., 2005), etc. Today, the most widely accepted noninvasive method for measuring endothelial function is ultrasound imaging of the brachial artery following reactive hyperemia (Corretti et al., 2002), or often referred to as flow-mediated dilation (FMD). Peak dilation of the brachial artery is subsequently calculated as the greatest percent change from baseline brachial artery diameter.

Although technical aspects of performing FMD studies has been discussed extensively (Corretti et al., 2002; Barac, Vampia \& Panza, 2007; Peretz et al., 2007; Thijssen et al., 2011 Flammer et al., 2012; Marlatt et al., 2012), there are still diverse techniques implemented among the scientific community (Peretz et al., 2007). Historically, researchers have measured FMD using a blood pressure occlusion cuff at various locations along the arm, from the upper arm above the ultrasound probe (Peretz et al., 2007) to the wrist (Doshi et al., 2001), yet the most widely accepted technique occludes the forearm (Peretz et al., 2007). Duration of occlusion has also been variable among studies (Corretti et al., 2002; Harris et al., 2010; Thijssen et al., 2011), though the most widely implemented occlusion time is 5 -minutes as it induces a response predominantly endothelium meditated and nitric oxide dependent (Corretti et al., 2002; Barac, Vampia \& Panza, 2007; Harris et al., 2010; Thijssen et al., 2011). Baseline brachial artery diameter assessment technique has also been variable among the scientific 
community (Herrington et al., 2001; Thijssen et al., 2008; Harris et al., 2010). To our knowledge, only one study has investigated the impact of baseline brachial artery diameters determined at differing time-points on peak FMD and that study only examined two common brachial artery locations (Thijssen et al., 2008). Currently, three differing baseline brachial artery diameter measures are being used in peak FMD determination within the literature (Herrington et al., 2001; Thijssen et al., 2008). In this study, we examined the potential effect of these three diameter measures of the brachial artery on the determination of peak FMD. To our knowledge, the impact of these three time-point measurements of brachial baseline diameter has not been fully investigated. Concurrent with previous research comparing two differing time-point baseline measures, it is hypothesized that the three differing time-point baseline measurements will be significantly different, thus producing a significant difference in subsequent peak FMD calculations.

A complete literature review, as well as a subsequent methodology, results, discussion, and conclusion surrounding the proposed study are detailed in the following chapters:

Chapter two summarizes the current literature related to FMD, documenting the technique as a well-validated means of assessing endothelial dependent function. Healthy and disease population differences in EDD will be discussed. 
Chapter three focuses on the methodology of this study. Background information surrounding the study population; data collection and measurement techniques, including anthropometric, blood pressure, and vascular assessments; as well as statistical analysis are stated.

Chapter four details the findings of this study, by examining the demographic characteristics of the study population: height, weight, body mass index, and hemodynamics. Differences among mean baseline time-point measurements and subsequent peak FMD in the study population are also reported.

Chapter five summarizes and discusses the implications of these findings with reference to the current literature. Results of baseline diameter differences after gender and age adjustment are discussed. Further discussion of baseline diameter implication on peak FMD is also reviewed.

Chapter 6 poses conclusions of the resulting study, as well as states the necessity for future research within FMD assessment in children and adults. 


\section{CHAPTER 2. REVIEW OF LITERATURE}


The cardiovascular system is composed of the heart, arterial and venous blood vessels. The innermost layer of an arterial blood vessel is the endothelium, which functions as a regulator of pathological and physiological processes such as smooth muscle tone, thrombosis, and inhibiting adhesion of leukocyte and platelet cell (Vane, Anggard, and Botting, 1990; Rubanyi, 1993; Celermajer et al., 1997; Harris et al., 2010). Little was known about the endothelium previous to the work of Dr. Robert Furchgott in the late 1970s and 1980s, with the endothelium being solely thought of as a physical barrier between the vessel wall and blood in the lumen.

In 1980, Nature published a manuscript by Furchgott describing the obligatory role of the endothelium in rabbit atrial vasculature and endothelial-derived releasing factor (EDRF) in controlling vascular tone, specifically smooth muscle relaxation with administration of acetylcholine (ACh) (Furchgott and Zawadzki, 1980). Acetylcholine was previously known to be a potent vasodilator in vivo, but in vitro experimentation with isolated smooth muscle were not always producing relaxation of the blood vessels (Furchgott and Zawadzki, 1980). The groundbreaking study demonstrated that in vitro relaxation by ACh of isolated preparations of rabbit thoracic aorta and other blood vessels requires the presence of endothelial cells, and that ACh stimulates the release of a substance that causes relaxation of the vascular smooth muscle (Furchgott and Zawadzki, 1980). It was concluded that endothelial cell activation regulated blood vessel dilation and constriction (Furchgott and Zawadzki, 1980). By the end of the decade, nitric oxide (NO) and EDRF were discovered to be synonymous (Palmer et al., 1987). 


\section{Assessing Vascular Function}

The endothelium is involved in many pathological and physiological processes, including the regulation of smooth muscle tone, control of thrombosis, inhibition of leukocyte and platelet cell adhesion and promotion of intra-arterial permeability (Vane et al., 1990; Rubanyi, 1993; Celermajer et al., 1997; Harris et al., 2010). In addition, there are numerous vasoactive substances released from the endothelium: prostacyclins, endothelins, endothelial cell growth factors, interleukins, plasminogen inhibitors and NO (Raitakari and Celermajer, 2000; Harris et al., 2010). Generally, a loss of NO bioavailability indicates a dysfunction across many properties of the endothelium. A number of cardiovascular risk factors are associated with endothelial dysfunction, and the modification of these risk factors often leads to an improvement in vascular function (Bonetti et al., 2003; Flammer et al., 2012). Endothelial dysfunction was first demonstrated in atherosclerotic coronary arteries using intracoronary infusions of ACh during coronary angiography by Ludmer and colleagues (Ludmer et al., 1986). Formerly thought to be purely a structural disease, Ludmer and colleagues drew attention to the functional manifestation of atherosclerosis, such as exaggerate vasoconstriction due to poor endothelial function. Later, less invasive techniques were developed to assess vascular beds ranging from the brachial artery using flow-mediated dilation (FMD) to finger microvasculature (EndoPAT) (Flammer et al. 2012). Commonly used techniques to assess endothelial function incorporate either a pharmacological or physical stimuli, such as cold pressor, exercise, or occlusion cuff (Flammer et al., 2012). The use of an 
occlusion cuff can result in reactive hyperemia (Celermajer et al., 1992), which is defined as the increase in blood flow which occurs immediately following the release of complete arterial occlusion (Webb and Myers, 1979).

\section{Physiological Response to Reactive Hyperemia}

Many blood vessels respond to an increase in blood flow, or shear stress, through vasodilation (Corretti et al., 2002). Reactive hyperemia causes an increase in vascular blood flow and shear stress on the endothelium, which open calcium-activated potassium channels of the endothelial cell membrane (Olesen et al., 1988; Cooke et al., 1991; Muira et al., 2001; Corretti et al., 2002). The opening of potassium channels hyperpolarizes the endothelial cell, driving calcium entry thereby activating the enzyme endothelial nitric oxide synthase (eNOS). Endothelial nitric oxide synthase generates the release of NO (Pohl et al., 1985; Joannides et al., 1995; Corretti et al., 2002). There is some redundancy in the system, as endothelium-derived prostanoids also respond to shear stress in the absence of eNOS and can signal smooth muscle relaxation (Sun et al, 1999; Corretti et al, 2002). However, $\mathrm{NO}$ is the primary endothelial vasodilator that dictates relaxation of smooth muscle cells and vasodilation (Corretti et al, 2002).

\section{Endothelium-Dependent Dilation}

In the early 1990s, Celermajer and colleagues devised a noninvasive method for testing endothelial function, referred to as flow-mediated dilation (FMD)(Celermajer et al., 1992). Since those early studies (Celermajer et al., 1992; Joannides et al., 1995), flow 
mediated vasodilation of the brachial artery has become the most widely used technique to measure endothelial function (Corretti et al., 2002; Flammer et al., 2012). The incorporation of high resolution ultrasound, combined with computer imaging technology is commonly used to measure brachial artery diameter changes for the determination of endothelial-dependent vasodilation, or EDD (Corretti et al., 2002; Williamson, Bronas, and Dengel, 2008). When measured appropriately, the assessment of endothelial function via FMD has been suggested to represent a functional bioassay for endothelium-derived NO bioavailability in humans (Corretti et al., 2002; Green, 2005; Harris et al., 2010). Assessment of endothelium-dependent vasomotion with brachial artery ultrasound has a high sensitivity and an excellent negative predictive value for coronary artery disease (Kuvin et al., 2001).

Consequently, flow-mediated dilation has been applied to both healthy and diseased subject groups, including children and young adults (Raitakari and Celermajer, 2000) and endothelial dysfunction has been demonstrated in asymptomatic children and adults with risk factors for atherosclerosis (Celermajer et al., 1992; Raitakari and Celermajer, 2000). Adults with coronary artery disease that are younger than 40 year have been shown to have impaired flow-induced vasodilation (Lieberman et al., 1996). Flow-mediated dilation is often diminished in older adults, which, along with brachial artery diameter, may have similar predictive values for cardiovascular events in older adults (Yeboah et al., 2007) or an age-associated decline in FMD may be partly attributed to diminished smooth muscle responsiveness (Parker, Ridout \& Proctor, 2006). 
Additional factors affecting vascular structure and function have also been investigated using EDD, such as obesity, weight loss, cigarette smoking and alcohol (Dengel and Bronas, 2010). Obese and overweight subjects have been shown to have lower EDD compared to normal weight subjects when using FMD (Tounian et al., 2001; Woo et al., 2004; Williams et al., 2005; Olson et al., 2006) while weight loss has been shown to increase EDD (Williams et al., 2005; Pierce et al., 2008). Acute (Lekakis et al., 1998) and chronic (Celermajer et al., 1993; Kiowski et al., 1994; Zeiher, Schachinger \& Minners, 1995; Barua et al., 2001) cigarette smoking as well as passive smoking (Raitakari et al., 1999; Holay et al., 2004) has been correlated with a decrease in EDD while alcohol consumption and vascular health seem to be more contentious (Maiorano et al., 1999; Agewell et al., 2000). Endothelium-dependent dilatation of the brachial arteries has also appeared to closely correlate with that of coronary arteries (Anderson et al., 1995).

Further studies have demonstrated the presence of other cardiovascular risk factors effecting endothelial function. Endothelial dysfunction in hypercholesterolaemic subjects has been detected in coronary microvasculature as well as vascular beds outside of the coronary circulation (Chowienczyk et al., 1992). Hypertension and total cholesterol to high-density lipoprotein cholesterol ratio have been inversely correlated with endothelial function, proposed as the result of increased vascular oxidative stress and inflammation (Sugiura et al., 2011). Decreasing levels of low density lipoprotein cholesterol has been associated with increased endothelial function (Kuvin et al., 2005). 
Acute hyperinsulinemia was shown to impair conduit vessel endothelial function independent of insulin sensitivity and lipid profile (Campia et al., 2004). Acute hyperglycemia has also been observed to rapidly suppress endothelial-dependent vasodilation (Kawano et al., 1999).

\section{Flow Mediated Dilation (FMD) Technique}

Current recommendations for FMD assessment have refined the procedure introduced by Celermajer and colleagues (1992) to a more robust assessment of a true NO-dependent measurement of vascular endothelial function (Harris et al., 2010). Methodology can be separated into subject preparation, protocol, technique, and analysis. Subjects should be resting supine in a quiet, temperature controlled room (Corretti et al, 2002; Barac, Campia \& Panza, 2007; Harris et al., 2010; Thijssen et al., 2010; Flammer et al., 2012). Refrainment of food intake, vitamins, medication, tobacco use, caffeine and prior exercise is essential for consistent FMD assessment. Documenting menstrual cycle when the FMD study is performed is also necessary (Corretti et al, 2002; Barac, Campia \& Panza, 2007; Harris et al., 2010; Thijssen et al., 2010; Flammer et al., 2012), since endothelium-dependent, flow-mediated vasodilation is enhanced when serum estradiol levels are elevated (English et al., 1998). Baseline diameter has been examined before cuff inflation, with suggested use of a stereotactic probe-holding device to maintain the same ultrasound image of the anterior and posterior intimal surfaces throughout the assessment. Inflation of a syphgmomanometric cuff, which is placed on the forearm, to suprasystolic pressure for 5 minutes provides an ischemic stimulus. Images are captured 
with a high frequency ultrasound transducer. Acquiring images of the brachial artery should start 30 seconds prior to cuff release until 3 minutes post deflation to allow for measurement of pre-cuff release diameter measures and post deflation diameter as well as acquisition of pulse-wave Doppler velocity for quantification of shear stress (Corretti et al, 2002; Harris et al., 2010; Thijssen et al., 2010; Flammer et al., 2012). Continuous edge detection and wall tracking software should be used for analysis (Corretti et al, 2002;

Harris et al., 2010; Thijssen et al., 2010; Flammer et al., 2012). 
CHAPTER 3. METHODOLOGY 


\section{Experimental Subjects}

Four hundred eighteen healthy children (228 males, 190 females) and 533 adults (257 males, 276 females), who participated in a series of studies evaluating cardiovascular risk were included in this cross-sectional study. These subjects were assessed for peak FMD from three different baseline brachial artery measurements. The study protocol was reviewed and approved by the University of Minnesota Institutional Review Board and all participants and parents/guardians gave written informed assent and consent. The procedures followed in this study were in accordance with institutional review board and HIPAA guidelines. Subjects were fasted for at least 8 hours prior to the vascular assessment, and were asked to abstain from caffeine ingestion for at least 4 on the morning of testing and to avoid strenuous exercise or physical activity for 24 hours prior to the study visit.

\section{Physical Assessments}

Measurements for height and weight were obtained with a standard stadiometer (Ayrton, Model S100, Prior Lake, MN, USA) and electronic scale (ST Scale-Tronix, Serial No. 5002-8893, White Plains, NY, USA), respectively. Body mass index (BMI) was calculated as weight in kilograms $(\mathrm{kg})$ divided by height in meters-squared $\left(\mathrm{m}^{2}\right)$.

\section{Vascular Assessments}

Vascular testing was performed in the Vascular Biology Laboratory in the Clinical and Translational Science Institute (CTSI) on the Minneapolis campus of University of Minnesota. Subjects were tested in a quiet, climate-controlled room (22- 
$23^{\circ} \mathrm{C}$ ). Resting blood pressure was recorded using an automated sphygmomanometer (Colin Medical Instruments Corp., San Antonio, TX, USA) on the right arm prior to FMD assessment. Following 15 minutes of quiet rest in the supine position, vascular images of the left brachial artery were obtained proximal to the antecubital fossa in the longitudinal plane using a conventional ultrasound scanner (Acuson, Sequoia 512, Siemens Medical Solutions USA, Inc., Mountain View, CA, USA) with a 8-15 MHz linear array probe held at a constant pressure on the skin and at a fixed point over the imaged artery by a stereotactic arm. A blood pressure (sphygmomanometeric) cuff was then placed on the left forearm. Pre-occlusion, occlusion and post-occlusion baseline brachial artery diameter measures were then assessed. Pre-occlusion baseline diameter was defined as a 10-second average before blood pressure cuff inflation. Occlusion baseline diameter was established as a 10-second average just prior to blood pressure cuff release. Post-occlusion baseline diameter was determined from a 10-second average immediately following the release of the blood pressure cuff.

Following pre-occlusion baseline diameter measurement, the blood pressure cuff on the left forearm was inflated to a suprasystolic pressure level of $200 \mathrm{mmHg}$ and maintained for 5 minutes. Vascular images were captured 20-seconds prior to cuff release until 3 minutes post cuff release. All images were digitized and stored on a personal computer for later off-line analysis using an electronic wall-tracking software program (Vascular Research Tools 5, Medical Imaging Application, LLC, Iowa City, IA, USA). Vascular images were assessed and baseline brachial artery measurements were recorded 
as averages of specified time-points. The electronic wall-tracking software was also used to ascertain maximal brachial artery dilation captured following reactive hyperemia. To calculate peak FMD, each subject's unique maximum brachial artery diameter was used to calculate the percent change from pre-occlusion, occlusion and post-occlusion baseline diameters.

\section{Statistical Analysis}

All statistical analysis was performed using IBM SPSS Statistics 21 (IBM Corp. Released 2012. IBM SPSS Statistics for Windows, Version 21.0. Armonk, NY: IBM Corp.). Repeated measures ANOVA tests adjusted for age and gender were conducted among pre-occlusion, occlusion, and post-occlusion baseline, as well as peak FMD from baselines. Greenhouse-Geisser F-statistic and significance were reported for withinsubjects effects to correct for susceptibility of type I error due to statistical significance of assumed sphericity. Bonferroni comparisons among baselines as well as FMD changes were conducted to distinguish statistically significant within-subject effects. An alpha value of 0.05 was denoted as statistically significant. Children and adult baseline and FMD change were statistically analyzed separately. 
CHAPTER 4. RESULTS 
Mean demographic characteristics of healthy children and adults are displayed in Table 1. Children ranged from 6 to 17 years, with a mean age of 12 years $( \pm 3.2 \mathrm{yrs})$. Adults were between the age of 18 and 49 years, with a mean age of 37 years ( $\pm 6.6 y$ rs). Both groups had impartial composition of gender and healthy hemodynamic characteristics. The body mass index (BMI) for the adults was $29.1 \mathrm{~kg} / \mathrm{m}^{2}$ and $21.0 \mathrm{~kg} / \mathrm{m}^{2}$ in the children. The mean BMI percentile for the children in this study was 64 , which is within a healthy reference range (Kuczmarski et al., 2000).

Vascular assessment measures for children and adults are found in Figure 1. Baseline measurements in children $(3.15 \pm 0.51,3.14 \pm 0.50$ vs. $3.11 \pm 0.50 \mathrm{~mm})$ were not significantly different $(\mathrm{df}=1.273, \mathrm{~F}=1.797, \mathrm{P}=0.179)$. Similarly peak FMD $(6.77 \pm 5.78$, $6.93 \pm 4.03$ vs. $7.85 \pm 3.62 \%)$ was also not significantly different in children ( $\mathrm{df}=1.304$, $\mathrm{F}=1.602, \mathrm{P}=0.208)$.

As observed in children baseline measurements of the brachial artery in adults $(3.81 \pm 0.72,3.81 \pm 0.73$ vs. $3.79 \pm 0.73 \mathrm{~mm})$ were not significantly different $(\mathrm{df}=1.295$, $\mathrm{F}=1.641, \mathrm{P}=0.201)$. Peak FMD $(6.06 \pm 5.53,6.12 \pm 3.94$ vs. $6.62 \pm 3.70 \%)$ was also not significantly different in adults $(\mathrm{df}=1.312, \mathrm{~F}=1.293, \mathrm{P}=0.266)$. 


\section{CHAPTER 5. DISCUSSION}


The aim of this study was to examine the effect of the three different baseline measures of the brachial artery in the calculation of peak FMD. The findings of this present study indicate no statistically significant difference among pre-occlusion, occlusion, and post-occlusion baseline measurements and corresponding determination of peak FMD in healthy children or adults.

Unlike Thijssen et al. (2008), who observed pre-occlusion and occlusion baselines and peak FMD significantly different for both children and adults, no significant difference was found between these baselines or corresponding peak FMD in children or adults in the present study. The contradiction between the two study results may be explained in the slight difference in methods or differing sample sizes. The current study utilized a stereotactic arm to secure the ultrasound transducer, while Thijssen et al. (2008) did not specify the use of one. It is imperative to image the same section of the brachial artery throughout the vascular assessment and to ensure image quality and a stereotactic arm aids in image acquisition (Flammer et al., 2012). The difference in sample size between the current study (418 children and 533 adults) and Thijssen et al. (45 children and 31 adults) could also explain the conflicting results. When using a smaller sample size, statistical significance could occur by chance and thus provide little consequential support to the research (Carver, 1978). This could explain the significance found between pre-occlusion and occlusion baselines and subsequent FMD reported by Thijssen et al. (2008). Statistical significance in research is usually dependent on sample size, and when using a very large sample size, cautious interpretation of results can avoid reporting 
statistically significant mean difference when, from a research standpoint, the detected mean difference is small and insignificant (Carver, 1978). Both studies could thus be prone to type I errors, where a significant mean difference was reported when in reality there is not difference. The logic of "statistically significant but clinically insignificant" would only solidify the reported results of the current study due to no significant differences among baselines or FMD changes, following adjustment for age and gender, even with a large sample.

Sample demographics, specifically age, could also clarify the inconsistency in results between studies. Thijssen et al. (2008) examined children that on average were two years younger $(10.0 \pm 1.0 \mathrm{yrs})$ than the children examined in our study $(12.2 \pm 3.2 \mathrm{yrs})$. When comparing mean baseline brachial artery measures between studies, the current study had about $0.5 \mathrm{~mm}$ larger diameter for both pre-occlusion and occlusion baselines in children than Thijssen et al. (2008). The stage of adolescent development of the children sampled could attribute to the inconsistency in results between studies, although preocclusion and occlusion baselines were not significant for either children or adults in the current study. An alternative consideration could be the larger artery size of children in the current study allowed for less user error.

It is curious to consider the Bernoulli principle and its role in the differing timepoint baseline measures, specifically a post-occlusion baseline measurement. The Bernoulli principle, when related to transmural pressure, can explain a constriction of 
brachial artery diameter (Jiang et al., 2011; Turner, 2011) following occlusion cuff release. A substantial drop in mean intra-arterial pressure along the brachial artery is inevitable during peak hyperaemic flow resulting in a fall in transmural pressure (Jiang et al., 2011). Although the Bernoulli principle is physiologically established, it was not potent enough to produce a statistically significant difference among pre-occlusion, occlusion, and post-occlusion baseline measures in the current study. This could possibly be explained by varying degrees of peak hyperaemic flow and decline in transmural pressure of the brachial artery among subjects, causing inconsistence involvement in post-occlusion baseline calculation. Due to the large sample size, the inconsistency could be masked in the calculation of mean post-occlusion baseline.

The lack of statistical significance among differing time-point baseline measurements is an interesting finding in the current study. This would lead researchers to conclude that pre-occlusion, occlusion, and post-occlusion baselines could be interchangeable in methodology when using healthy children and adult subjects. Consequently, since a significant difference was not found between the investigated baseline measures or effect on peak FMD, then comparison of results utilizing these timepoint baseline measures could be conducted. Of course, these comparisons should be done with careful consideration. The findings of this present study aid in the development of standardized methodology for clinical assessment of cardiovascular fitness using flowmediated dilation. 
Strengths and Limitations

Study strengths include the considerably large sample size for detection of differences in baseline measures in healthy children and adults. One limitation of the present study is that all subjects were healthy children and adults. Secondly, flowmediated dilation techniques were performed by four trained professionals. Furthermore, generalization to less healthy populations is limited. Additionally, techniques that vary from 5-minute occlusion distal to the ultrasound probe cannot be compared with the findings of this study. The variance of time-point baseline measures could not be determined due to the cross-sectional nature of this study. 
CHAPTER 6. CONCLUSION 
Pre-occlusion, occlusion and post-occlusion baseline brachial artery diameter were not statistically different in our populations of healthy children and adults. Furthermore, no statistically significant difference among peak FMD change was observed. Therefore, comparison and compilation of data from studies utilizing different measures of baseline brachial diameter in healthy children and adults may be conducted. However, careful consideration should be used when choosing a baseline measure for non-healthy children and adult populations. Future studies could investigate non-healthy children and adults peak FMD from the three time-point baseline measure as well as examination of the variance of the three time-point baseline measurements by analyzing multiple brachial artery diameter assessments from the same subject to determine consistency. 


\section{CHAPTER 7. REFERENCES}


Agewall S, Wright S, Doughty RN, Whalley GA, Duxbury M, Sharpe N. Does a glass of red wine improve endothelial function? Eur Heart J 2000;21:74-78.

Anderson TJ, Uehata A, Gerhard MD, Meredith IT, Knab S, Delagrange D, Lieberman EH, Ganz P, Creager MA, Yeung AC, Selwyn S. Close relation of endothelial function in human coronary and peripheral circulations. J Am Coll Cardiol 1995;26:1235-1241.

Barac A, Campia U, Panza JA. Methods for evaluating endothelial function in humans. Hypertension 2007;49:748-760.

Barua RS, Ambrose JA, Eales-Rynolds LJ, DeVoe MC, Zervas JG, Saha DC. Dysfunctional endothelial nitric oxide biosynthesis in healthy smokers with impaired endothelium-dependent vasodilatation. Circulation 2001;104:19051910.

Bonetti PO, Lerman LO, Lerman A. Endothelial dysfunction: a marker of atherosclerotic risk. Arterioscler Thromb Vasc Biol. 2003;23:168-175.

Campia U, Sullivan G, Bryant MB, Waclawiw MA, Quon MJ, Panza JA. Insulin impairs endothelium-dependent vasodilation independent of insulin sensitivity or lipid profile. Am J Physiol Heart Circ Physiol 2004;286:H76-H82. 
Celermajer D, Sorensen K, Gooch V, Spielgelhalter D, Miller O, Sullivan I, Lloyd J, Deanfield J. Non-invasive detection of endothelial dysfunction in children and adults at risk of atherosclerosis. Lancet 1992;340:1111-1115.

Celermajer D. Endothelial dysfunction: does it matter? Is it reversible? J Am Coll Cardiol. 1997;30:325-333.

Celermajer D, Sorensen K, Spiegelhalter D, Georgakopoulos D, Bull C, Thomas O, Robinson J, Deanfield JE. Cigarette smoking is associated with dose-related and potentially reversible impairment of endothelium-dependent dilation in healthy young adults. Circulation 1993;88(5): 2149-55.

Chowienczyk P, Watts G, Cockcroft J, Ritter J. Impaired endothelium-dependent vasodilatation of forearm resistance vessels in hypercholesterolemia. Lancet 1992;340:1430-1432.

Cooke JP, Rossitch E, Andon NA, Loscalzo J, Dzau VJ. Flow activates an endothelial potassium channel to release an endogenous nitrovasodilator. $J$ Clin Invest 1991;88:1663-1671. 
Corretti M, Anderson T, Benjamin E, Celermajer D, Charbonneau F, Creager M, Deanfield J, Drexler H, Gerhard-Herman M, Herrington D, Vallance P, Vita J, Vogel R. International Brachial Artery Reactivity Task Force. Guidelines for the ultrasound assessment of endothelial-dependent flow mediated vasodilation of the brachial artery. J Am Coll Cardiol 2002;39(2):257-265.

Dengel DR, Bronas UG. The role of endothelial dysfunction on development and progression of atherosclerosis and methods to assess vascular function and structure. Am J Life Med 2010;4(5):445-456.

Doshi SN, Naka KK, Payne N, Jones CJ, Ashton M, Lewis MJ, Goodfellow J. Flow-mediated dilatation following wrist and upper arm occlusion in humans: the contribution of nitric oxide. Clinical Science 2001;101:629635.

English JL, Jacobs JO, Green G, Andrews TC. Effect of the menstrual cycle on endothelium-dependent vasodilation of the brachial artery in normal young women. Am J Cardiol 1998;82:256-258.

Flammer AJ, Anderson T, Celermajer DS, Creager MA, Deanfield J, Ganz P, Hamburg NM, Lüscher TF, Shechter M, Taddei S, Vita JA, Lerman A. The assessment of 
endothelial function: from research into clinical practice. Circulation 2012;126:753-767.

Furchgott RF, Zawadzki JV. The obligatory role of endothelial cells in the relaxation of arterial smoot muscle by acetylcholine. Nature 1980;288(5789):373-376.

Green D. Point: flow-mediated dilatin does reflect nitric oxide-mediated endothelial function. J Appl Physiol. 2005;99:1233-1234.

Harris RA, Nishiyama SK, Wray DW, Richardson RS. Ultrasound assessment of flowmediated dilation. Hypertension. 2010;55:1075-1085.

Herrington DM, Fan L, Drum M et al. Brachial flow-mediated vasodilator responses in population-based research: methods, reproducibility and effects of age, gender and baseline diameter. J Cardiovasc Risk. 2001;8:319-328.

Holay MP, Paunikar NP, Joshi PP, Sahasrabhojney VS, Tankhiwale SR. Effect of passive smoking on endothelial function in healthy adults. JAPI 2004;52:114-117.

Jiang B, Seddon M, Fok H, Donald A, Chowienczyk P. Flow-mediated dilation of the radial artery is offset by flow-induced reduction in transmural pressure. Hypertension 2011;57:1145- 1150. 
Joannides R, Haefeli WE, Linder L, et al. Nitric oxide is responsible for flow-dependent dilatation of human peripheral conduit arteries in vivo. Circulation 1995;91:13141319.

Kawano H, Motoyama T, Hirashima O, Hirai N, Miyao Y, Sakamoto T, Kugiyama K, Ogawa H, Yasue H. Hyperglycemia rapidly surpresses flow-mediated endothelium-dependent vasodilation of brachial artery. J Am Coll Cardiol 1999;34:146-154.

Kiowski W, Linder L, Stoschitzky K, Pfisterer M, Burckhardt D, Burkart F, Bühler FR. Diminished vascular response to inhibition of endothelium-derived nitric oxide and enhanced vasoconstriction to exogenously administered endothelin-1 in clinically healthy smokers. Circulation 1994;90:27-34.

Kuczmarski RJ, Ogden CL, Grummer-Strawn LM, Flegal KM, Guo SS, Wei R, Mei Z, Curtin LR, Roche AF, Johnson CL. CDC growth charts: United States. Advance data from vital and health statistics; no. 314. Hyattsville, Maryland: National Center for Health Statistics. 2000.

Kuvin JT, Patel AR, Sliney KA, Pandian NG, Karas RH. Comparison of flowMediated dilatation of the brachial artery in coronary patients with low- 
density lipoprotein cholesterol levels $<80 \mathrm{mg} / \mathrm{dl}$ versus patients with levels 80 to $100 \mathrm{mg} / \mathrm{dl}$. Am J Cardiol 2005;95(1):93-95.

Kuvin JT, Patel AR, Sliney KA, Pandian NG, Rand WM, Udelson JE, Karas RH. Peripheral vascular endothelial function testing as a noninvasive indicator of coronary heart disease. J Am Coll Cardiol 2001;38:1843-1849.

Lekakis J, Papamichael C, Vemmos C, Stamatelopoulos K, Voutsas A, Stamatelopoulos S. Effects of acute cigarette smoking on endotheliumdependent arterial dilatation in normal subjects. Am J Cardiol 1998;81:1225-1228.

Lieberman EH, Gerhard MD, Uehata A, Selwyn AP, Ganz P, Yeung AC, Creager MA. Flow-induced vasodilation of the human brachial artery is impaired in patients $<40$ years of age with coronary artery disease. Am J Cardiol 1996;78:1210-1214.

Ludmer PL, Selwyn AP, Shook TL, Wayne RR, Mudge GH, Alexander RW, Ganz P. Paradoxical vasoconstriction induced by acetylcholine in atherosclerotic coronary arteries. N Engl J Med 1986;315(17):1046-1051. 
Maiorano, Bartolomucci F, Contursi V, Minenna FS, Di Mise R, Palasciano A, Allegrini B, Amoruso M, Kozàkovà M. Noninvasive detection of vascular dysfunction in alcoholic patients. Am J Hypertens 1999;12(2):137-44.

Marlatt KL, Kelly AS, Steinberger J, Dengel DR. The influence of gender on carotid artery compliance and distensibility in children and adults. J Clin Ultrasound. 2012. (In Press).DOI: 10.1002/jcu.22015.

Mitchell GF, Vita JA, Larson MG, Parise H, Keyes MJ, Warner E, Vasan RS, Levy D, Benjamin EJ. Cross-sectional relations of peripheral microvascular function, cardiovascular disease risk factors, and aortic stiffness: the Framingham heart study. Circulation 2005;112:3722-3728.

Olesen SP, Clapham DE, Davies PF. Haemodynamic shear stress activates a K+ current in endothelial cells. Nature 1988;331:168-170.

Palmer R, Ferridge A, Moncada S. Nitric oxide release accounts for the biological activity of endothelium-derived relaxing factor. Nature 1987;327:524-526.

Parker BA, Ridout SJ, Proctor DN. Age and flow-mediated dilation: a comparison of dilatory responsiveness in the brachial and popliteal arteries. Am J Physiol Heart Circ Physiol 2006;291:H3043-H3049. 
Pohl U, Holtz J, Busse R, Bassenge E. Crucial role of endothelium in the vasodilator response to increased flow in vivo. Hypertension 1986;8:37-44.

Raitakari OT, Adams MR, McCredie RJ, Griffiths KA, Celermajer DS. Arterial endothelial dysfunction related to passive smoking is potentially reversible in healthy young adults. Ann Intern Med 1999;130:578-581.

Raitakari O, Celermajer D. Testing for endothelial dysfunction. Ann Med 2000;32:293304.

Rubanyi GM. The role of endothelium in cardiovascular homeostasis and disease. J Cardiovasc Pharmacol. 1993;22:S1-S14.

Sugiura T, Dohi Y, Yamashita S, Yamamoto K, Wakamatsu Y, Tanaka S, Kimura G. Impact of lipid profile and high blood pressure on endothelial damage. $J$ Clin Lipidol 2011;6:460-466.

Turner MJ. Is pressure decrease at peak hyperemia attributed to Poiseuille or Bernoulli or both? Hypertension 2011;58:e21. 
Vane JR, Anggard EE, Botting RM. Regulatory functions of the vascular endothelium. $N$ Engl J Med. 1990;323:27-36.

Thijssen DH, Black MA, Pyke KE, Padilla J, Atkinson G, Harris RA, Parker B, Widlansky ME, Tschakovsky ME, Green DJ. Assessment of flow-mediated dilation in humans: a methodological and physiological guideline. Am J Physiol Heart Circ Physiol 2011;300:H2-H12.

Thijssen DH, van Bemmel MM, Bullens LM, Dawson EA, Hopkins ND, Tinken TM, Black MA, Hopman MT, Cable NT, Green DJ. The impact of baseline diameter on flow-mediated dilation differs in young and older humans. Am J Physiol Heart Circ Physiol 2008; 295(4):H1594-H1598.

Webb RC and Myers JH. Skeletal muscle capillary densities during reactive hyperemia. Experientia 1979;35(11):1476-1477.

Williamson EB, Bronas UG, Dengel DR. Automated edge detection versus manual edge measurement in anaylsis of brachial artery reactivity: a comparison study. Ultrasound in Med. \& Biol. 2008;34(9):1499-1503. 
Yeboah J, Crouse JR, Hsu F, Burke GL, Herrington DM. Brachial flow-mediated dilation predicts incident cardiovascular events in older adults: the cardiovascular health study. Circulation 2007;115:2390-2397.

Zeiher AM, Schachinger V, Minners J. Long-term cigarette smoking impairs endothelium-dependent coronary arterial vasodilator function. Circulation 1995;92:1094-1100. 
Table 1. Mean ( \pm Standard Deviation) Demographic Characteristics

\begin{tabular}{lll}
\hline & Children & Adults \\
\hline Number (\% male) & $418(55 \%)$ & $533(48 \%)$ \\
Age, yrs & $12.2 \pm 3.2$ & $37.0 \pm 6.6$ \\
Blood pressure, mmHg & $112 \pm 12$ & $124 \pm 16$ \\
Systolic & $58 \pm 8$ & $72 \pm 11$ \\
Diastolic & $153.5 \pm 17.7$ & $171.2 \pm 10.8$ \\
Height, cm & $51.6 \pm 21.1$ & $85.6 \pm 23.8$ \\
Weight, kg & $21.0 \pm 5.2$ & $29.1 \pm 7.6$ \\
Body Mass Index, $\mathrm{kg} / \mathrm{m}^{2}$ & & \\
\hline
\end{tabular}

Note: Values are means \pm SD. 

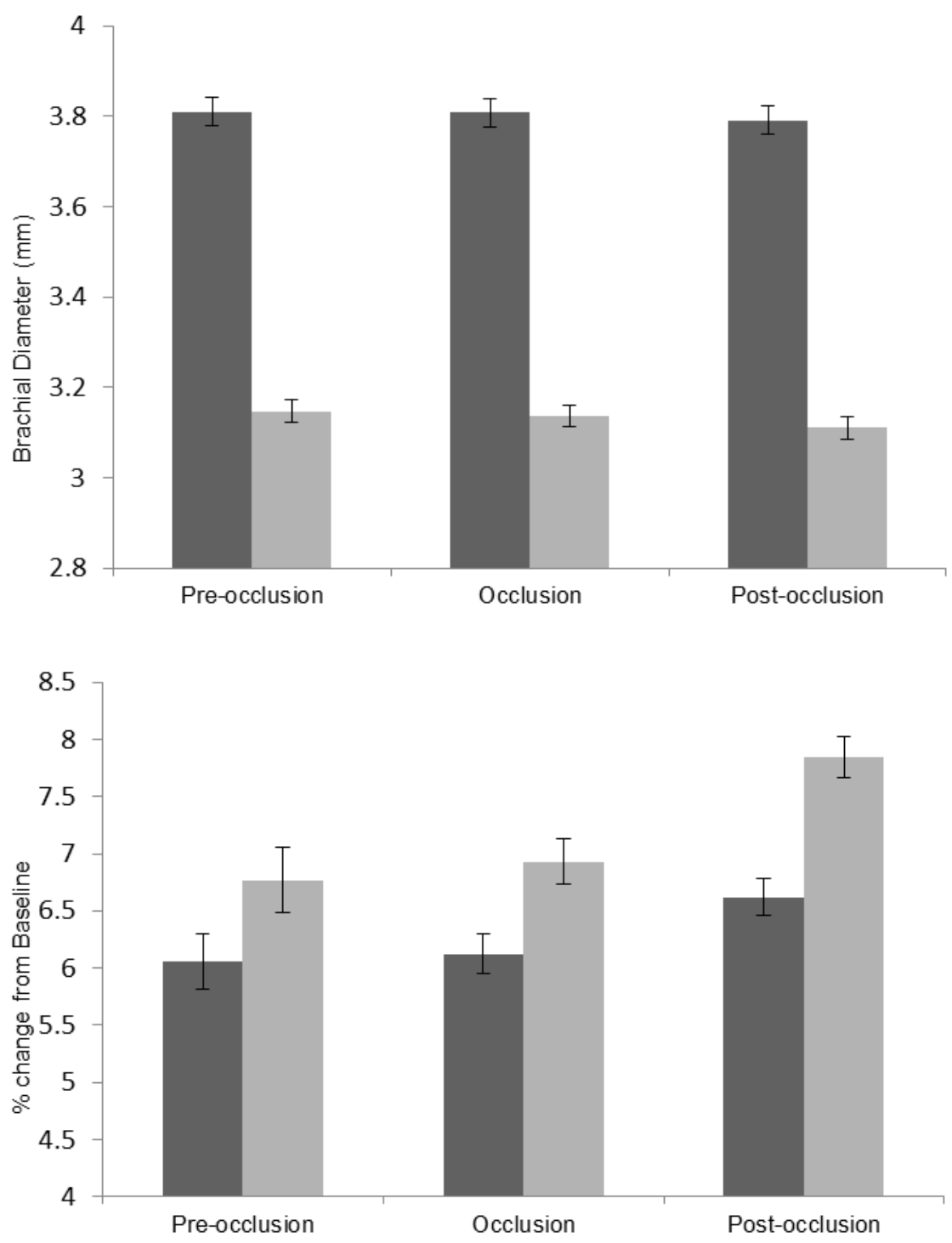

Figure 1. Mean ( $₫$ standard error) baseline brachial artery and flow-mediated dilation comparison measures for children and adults.

Average baseline brachial artery diameter and percent change from baseline for 533 adults ( $\square$ ) and 418 children ( $\square$ ) are displayed with SEM bars for pre-occlusion, occlusion, and post-occlusion measures. 